\section{Severe Cardiovascular Complication Associated with Prolonged Starvation}

\author{
F. SANDHOFER, F. DIENSTL, K. BOLZANO, \\ H. SCHWINGSHACKL
}

British Medical fournal, 1973, 1, 462-463

Obesity must be regarded as a serious medical problem. Total starvation, which appears to be the most effective method for reduction of overweight, is generally considered to be without serious risk, even when prolonged, for obese but otherwise healthy people. Until now only one death attributable to therapeutic starvation in a healthy person has been reported (Garnett et al., 1969). We describe here the case of a 37-yearold woman who developed severe cardiovascular symptoms with marked electrocardiographic abnormalities after 18 weeks of therapeutic starvation.

\section{Case Report}

At the age of 3 years the patient had poliomyelitis, after which she was able to walk only with difficulty. After puberty she steadily gained weight. At the ages of 21, 30, and 33 she was delivered of healthy children. After the third delivery she took oral contraceptives periodically. At the age of 36 her weight was $121 \mathrm{~kg}$, and her height $158 \mathrm{~cm}$. She complained of severe pain in the lumbar spine and was hardly able to walk.

At the age of 37 she was admitted to our clinic for weight reduction. On admission her weight was $108 \mathrm{~kg}$. Clinical examination was unremarkable, and blood, urine, and $x$-ray investigations showed nothing abnormal apart from osteoarthritis of the right hip joint and a lumbar disc lesion.

She was treated under close supervision on a metabolic ward with an acaloric diet and 2 litres of fluid (mineral water or plain tea) daily. She was given supplements of vitamins and 1 teaspoonful of El-oral ${ }^{*}$ three times a day. During the first week of starvation the serum uric acid concentration rose to $11.6 \mathrm{mg} / 100 \mathrm{ml}$, so allopurinol was given (400 mg/day for two weeks, then $300 \mathrm{mg} /$ day). The serum concentrations of electrolytes, transaminases, urea nitrogen, and uric acid were estimated and electrophoresis of the serum proteins was carried out regularly; these values remained in the normal range throughout the whole starvation period.

During the first two weeks base excess in blood as measured by the Astrup method was between -10.9 and $-8 \mathrm{mEq} / 1$. and the pH of the blood was between $7 \cdot 27$ and 7.30; subsequently the base excess was between -3 and $-1 \mathrm{mEq} / 1$., and the $\mathrm{pH}$ between 7.36 and 7.39. Severe ketonuria was present throughout the whole starvation period. Blood pressure varied between $100 / 70$ and $120 / 80 \mathrm{~mm} \mathrm{Hg}$, and the heart rate was about $80 / \mathrm{min}$. Three months after the beginning of starvation $x$-ray examination of the chest was repeated and gave a normal result. Total starvation was continued for 18 weeks without complication. The patient felt relatively well and went for short walks every day. During the 18 weeks of total fasting she lost $35 \mathrm{~kg}$ of weight (mean daily loss $278 \mathrm{~g})$.

On the 129th day of starvation she undertook an excursion accompanied by a nurse and returned in a severely exhausted state. She showed symptoms of severe shock, the heart rate was $120 / \mathrm{min}$, and systolic blood pressure had fallen to $60 \mathrm{~mm} \mathrm{Hg}$. An E.C.G. showed sinus tachycardia, P-R interval $0.16 \mathrm{sec}$, pronounced low voltage, left axis deviation, isoelectric S-T segments

*One teaspoon contains $25 \mathrm{mEq} \mathrm{Na}, 10 \mathrm{mEq} \mathrm{K}, 2 \mathrm{mEq} \mathrm{Ca}, 2 \mathrm{mEq} \mathrm{Mg}$ $15 \mathrm{mEq}$ citrate, $2 \mathrm{mEq}$ lactate, $15 \mathrm{mEq} \mathrm{Cl}, 2 \mathrm{mEq}$ sulphate, and 5 mEq phosphate.

Department of Medicine, University of Innsbruck, Austria

F. SANDU OFER, M.D., Dozent.

F. DIENSTL, M.D., Dozent

K. BOL7ANO, M.D., Senior Assistant.

H. SCHWINGSHACKL, M.D., Senior Assistant. in all standard limb leads, and a convex upward elevation of the S- $T$ segment in leads $V_{2}$ and $V_{3}$; the $T$ wave was slightly inverted in leads $I$ and aVL, markedly inverted in $V_{2}$ and $V_{3}$, and upright in the remaining precordoial leads (fig. 1). She received plasma expanders, laevulose solution, and metaraminol. The cardio vascular signs and symptoms persisted with unchanged severity for the next two days. Starvation was then discontinued. At that time she weighed $73 \mathrm{~kg}$ and had not achieved her predicted ideal weight of $57 \mathrm{~kg}$. Strict bed rest was ordered.

Her diet was 200 calories for the first two days, 500 calories for the next two days, and 800 calories for the following week$35 \%$ protein, $30 \%$ fat, and $35 \%$ carbohydrate. She was then given a 1,000-calorie diet, which maintained a constant body weight. The serum electrolyte, protein, and transaminase levels were determined immediately after the acute event and regularly during the following days; they always remained within the normal range. A state of fairly severe exhaustion persisted throughout subsequent weeks. Blood pressure was between $100 / 50$ and $100 / 70 \mathrm{~mm} \mathrm{Hg}$, pulse rate between 60 and $80 / \mathrm{min}$. There were no signs of heart failure at any time.

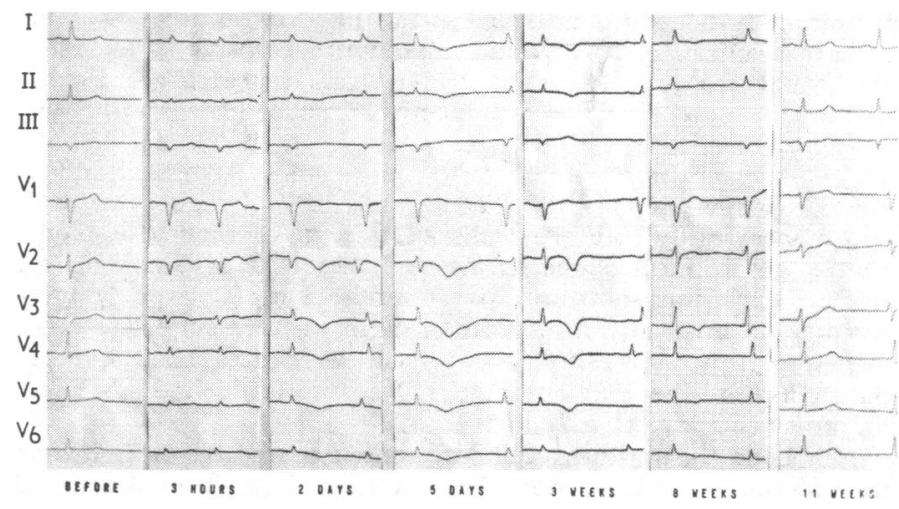

FIG. 1-Electrocardiographic findings (standard limb leads and precordial leads) before starvation, and at different times after onset of cardiovascular symptoms.

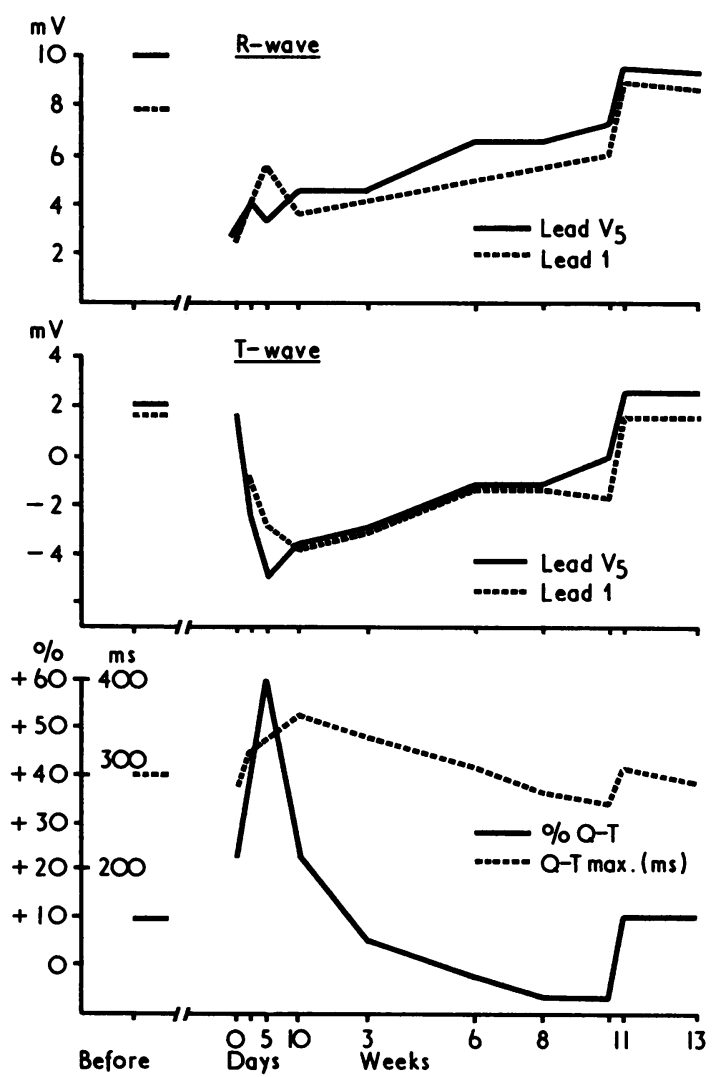

FIG. 2-Amplitude of $R$ and $T$ waves ( $\mathrm{mV}$ ), duration of Q-T interval (interval between $Q$ wave and maximum height of $T$ wave), and change in Q-T interval as percentage of the normal heart rate. 
The major E.C.G. changes were a very pronounced general low voltage and a marked prolongation of the electrical systole (figs. 1 and 2). The low voltage was most pronounced immediately after the onset of the cardiac symptoms, improved slowly thereafter, and disappeared after 11 weeks; it was noticeable mostly in the peripheral and left precordial leads. In contrast to the low voltage the Q-T interval was only slightly prolonged immediately after the onset of the acute attack and reached its maximum five days later $(0.62 \mathrm{sec}$-that is, a prolongation of $59 \%$ over the normal for the given heart rate). The $Q-T$ interval had returned to normal three weeks later although the voltage was still low. Another noticeable feature was the negative $T$ wave in leads I, II, aVL, and $V_{2}-V_{6}$, suggesting a subepicardial lesion. This inversion of the $T$ wave lasted 11 weeks.

During the first four weeks after the acute attack the patient complained of extreme weakness and occasional anginal symptoms. The chest radiograph remained normal. In the course of the next few weeks her symptoms gradually subsided and she became able to walk again without difficulty for short distances. She was discharged from the clinic 11 weeks after the onset of the cardiac symptoms. At that time the E.C.G. showed no difference compared with the findings before the starvation period (fig. 1).

\section{Comment}

Prolonged total starvation is generally well tolerated by obese but otherwise healthy persons and has been maintained for periods up to 249 days without any complications (Thomson et al., 1966). On the other hand, sudden death as a con- sequence of total caloric restriction of relatively short duration has been reported in persons with pre-existing signs of heart failure or myocardial damage (Spencer, 1968). Moreover, Garnett et al., (1969) recorded the sudden death from ventricular fibrillation of a healthy woman aged 20 seven days after the termination of $\mathbf{3 0}$ weeks of total starvation for the treatment of obesity-12 weeks longer than in the present case. Shortly before death the E.C.G., which had been normal one month previously, showed low voltage and prolongation of the Q-T interval, which apparently were not caused by a disturbance of the electrolyte levels. The patient had already regained her ideal weight. Garnett et al., suggested that the changes in the E.C.G. and the sudden death of their patient were due to gross protein loss causing massive destruction of the cardiac myofibrillae.

We suggest that in grossly obese but otherwise healthy persons therapeutic starvation may be carried out under close supervision for three to four weeks. The fast should then be followed by a low-calorie diet, with possibly one or two days of total fasting per week. If necessary starvation may be repeated later for a similar period.

\section{References}

Garnett, E. S., Barnard, D. L., Ford, J., Goodbody, R. A., and Woodehouse, M. A. (1969). Lancet, 1, 914

Spencer, I. O. B. (1968). Lancet, 1, 1288.

Thomson, T. J., Runcie, J., and Miller, V. (1966). Lancet, 2, 992.

\section{Spontaneous Oesophageal Rupture after Carbachol Therapy}

\section{P. COCHRANE}

British Medical fournal, 1973, 1, 463-464

For many years carbachol has been used to promote emptying of a distended urinary bladder. More recently Goodman and Gilman (1970) have drawn attention to untoward side effects of the drug. A case of oesophageal rupture after the administration of carbachol is described here.

\section{Case Report}

A 58-year-old man was admitted to hospital with a history of having vomited some reddish-black material two hours previously after a subcutaneous injection of carbachol given to relieve urinary retention. The vomiting was immediately followed by severe central chest pain and increasing breathlessness. His doctor arranged his admission to hospital with a presumptive diagnosis of myocardial infarction.

On admission he was restless, breathless, and in considerable chest pain, with a pulse rate of $100 / \mathrm{min}$ and a blood pressure of $140 / 90$ $\mathrm{mm} \mathrm{Hg}$. Generalized inspiratory and expiratory rhonchi were audible. An electrocardiogram showed no evidence of a myocardial infarction but this was thought to be the most likely diagnosis, with dissection of the aorta as an alternative. Two hours later, when he had become even more breathless and cyanosed and congestive changes were present on chest $x$-ray examination, a pulmonary embolus was suspected. Over the next 12 hours the condition was unchanged and a

Walton Hospital, Liverpool L9 1AE

P. COCHRANE, M.D., M.R.C.P., Senior Medical Registrar diagnosis of ruptured oesophagus was made after a bloodstained, leftsided pleural effusion had been aspirated. By this time surgical emphysema was present in the neck, and radiography showed mediastinal emphysema and a left-sided hydropneumothorax. At a left-side thoracotomy 22 hours after the onset of symptoms the left pleural cavity was found to be filled with black fluid, the lung and chest wall covered with fibrin, and the mediastinum quite distended. The pleura was opened and the lower $8 \mathrm{~cm}$ of the oesophagus dissected, revealing a $3-\mathrm{cm}$ tear in the posterior wall. This was repaired.

On the third postoperative day the suture line gave way, and an oesophageal leak was confirmed by a Gastrografin swallow. Left pleural drainage was maintained and on the ninth day oesophagoscopy confirmed this complication. Later a right-sided pleural effusion was also drained. On the 12th day a tracheostomy was performed because the chest condition was deteriorating, and the patient was maintained with intermittent positive pressure ventilation. This was discontinued on the 17th day and the tracheostomy tube was removed six days later. Unfortunately, on the 24th day he developed a pyrexia of $40^{\circ} \mathrm{C}$ associated with a left-sided empyema and he died after a cardiac arrest the next day. Permission for a postmortem examination was refused.

\section{Comment}

The term "spontaneous" oesophageal rupture should not imply a previously normal oesophagus or an absence of other precipitating factors (Anderson, 1957). Perhaps "post-emetic" is a more descriptive term, though the rupture may occur without vomiting after physical straining, childbirth, and seizures (Tesler and Eisenberg, 1963). In $80 \%$ of cases spontaneous oesophageal ruptures occur in men in their fifth or sixth decades, typically after food or alcoholic overindulgence. It still has a mortality of $30 \%$, partly owing to delayed diagnosis and to preexisting oesophageal disease (Wychulis et al., 1969). In the present case failure to appreciate the characteristic symptomsequence of vomiting, chest pain, and dyspnoea led to delay in diagnosis. Pre-existing oesophageal disease was not noted at the operation but a postmortem examination was not performed.

Carbachol is a cholinergic drug which until recently has been used in the emergency treatment of acute urinary retention. It 